\title{
On Rhetorical Functions and Structural Patterns of Analogy
}

\author{
Yan Chang \\ Foreign Language School, Qingdao University of Science and Technology, Qingdao, China \\ Email: changyan27@163.com
}

\begin{abstract}
Analogy as "the core of cognition", plays a significant role in many aspects of our life, including problem solving, decision making, perception, memory, creativity, emotion, explanation and communication. Its specific explanations differ with various disciplines and subjects. The author mainly discusses about analogy in linguistic sense, especially in rhetorical sense. Its popularity as a rhetorical device lies in its clarity, appeal and persuasiveness. After comparison analogy with simile/metaphor, the writer elucidates its distinct rhetorical functions - for the purpose of persuasion or for the explanation or exposition of an idea. The structural patterns which are distinctly marked but frozen and fixed have also been analyzed with illustrations.
\end{abstract}

Index Terms — rhetorical device, analogy, rhetorical function, structural pattern

\section{INTRODUCTION}

Analogy (from Greek analogia), according to Wikipedia, "is a cognitive process of transferring information or meaning from a particular subject (the analogue or source) to another particular subject (the target)."

In a narrower sense, analogy is an inference or an argument from one particular to another particular, as opposed to deduction, induction, and abduction, where at least one of the premises or the conclusion is general.

It, considered as "the core of cognition", plays a significant role in many aspects of our life, including problem solving, decision making, perception, memory, creativity, emotion, explanation and communication.

As an important method of thinking, analogy is widely applied in the processes of creation, comprehension and education; and it manifest itself in varies fields including deducing and inducing in natural sciences, literature creation and even word coining in different disciplines. It is important not only in ordinary language and common sense, but also in science, philosophy and the humanities. What's more, its definitions differ with various disciplines and subjects. This paper mainly discusses about analogy in linguistic sense, especially in rhetorical sense.

\section{ANALOgy as a RhETORICAL Device}

Its popularity as a figure of speech lies in its clarity, appeal and persuasiveness, what' more, it is also an effective method of practicing the ability of thinking. As for the content of analogy, there are mainly four categories - analogies based on personal experience, analogies based on personal knowledge, analogies based on daily life and analogies based on imagination.

\section{A. Definition}

What is an analogy? "An analogy is a comparison in which different items are compared point by point, usually with the idea of explaining something unknown by something known." Analogies tend to suggest that existing similarities imply even more similarities.

Analogy as a rhetorical device is a form of comparison, but unlike simile or metaphor, which usually concentrates on one point of resemblance, analogy draws a parallel between two unlike things that have several common qualities of points of resemblance. Here is an instance:

I look at this as being in the form of a house. And the students are the foundation, and the teachers are the walls, and the roof itself is the school. And we know that if you have a weak foundation, the walls and the roof can't be supported. Therefore, it crumbles.

In this example, three points of resemblance are paralleled to explain the significance of students in a school.

\begin{tabular}{|l|l|l|}
\hline & Tenor & Vehicle \\
\hline & House & School \\
\hline \multirow{2}{*}{$\begin{array}{l}\text { Paralleled } \\
\text { Similar Points }\end{array}$} & The foundation & The students \\
\cline { 2 - 3 } & The walls & The teachers \\
\cline { 2 - 3 } Conclusion & The roof & The school \\
\hline & $\begin{array}{l}\text { The foundation is the basic and most } \\
\text { essential element of an entire building. }\end{array}$ & $\begin{array}{l}\text { Students play the most important role in a } \\
\text { school and should come first. }\end{array}$ \\
\hline
\end{tabular}


Many famous people have also used analogies to explain their positions or their opinions on an issue. For instance, consider the following analogy examples:

1) "I am to dancing what Roseanne is to singing and Donald Duck to motivational speeches. I am as graceful as a refrigerator falling down a flight of stairs." - Leonard Pitts, "Curse of Rhythm Impairment" Miami Herald, Sep. 28, 2009

2) "If you want my final opinion on the mystery of life and all that, I can give it to you in a nutshell. The universe is like a safe to which there is a combination. But the combination is locked up in the safe." Peter De Vries, Let Me Count the Ways

3) "Writing a book of poetry is like dropping a rose petal down the Grand Canyon and waiting for the echo." - Don Marquis

4) "They crowded very close about him, with their hands always on him in a careful, caressing grip, as though all the while feeling him to make sure he was there. It was like men handling a fish which is still alive and may jump back into the water." - George Orwell, A Hanging

5) "Withdrawal of U.S. troops will become like salted peanuts to the American public; the more U.S. troops come home, the more will be demanded." - Henry Kissinger in a Memo to President Richard Nixon

6) "... worrying is as effective as trying to solve an algebra equation by chewing bubble gum." - Baz Luhrmann, Everybody's Free (to Wear Sunscreen)

7) "Dumb gorgeous people should not be allowed to use literature when competing in the pick-up pool. It's like bald people wearing hats." - Matt McGrath from the movie Broken Hearts Club

\section{B. Linguistic Reliance of Analogy on Simile/Metaphor}

The analogy can be developed through as many parallel similarities as the writer can think of, to convince the reader that because the things are alike in so many respects, a conclusion drawn from one suggests a similar conclusion from the other.

It is acknowledged that all metaphors and similes are based on analogy. But an analogy compares two things not only in one aspect as a simile or a metaphor does, but also taps between the two things as many similarities as possible and then develops them so as to make the comparisons more outstanding and effective. The following are some examples:

1) Followers are to a leader as planets are to a sun.

2) Shells were to ancient cultures as dollar bills are to modern culture.

3) (Just) as dark clouds cannot long hide the sun, (so) no lies can cover up facts.

4) The surface of the earth is like the skin of an orange, which cannot be spread out flat unless it is torn into strips. That's why flat maps of the whole earth always distort its appearance.

Typical comparative word "as" "just as..., so..." and "like" are used to introduce the vehicle, connecting the two terms (tenor and vehicle). Just due to its similarity with metaphor and simile in sentence structure, some experts even think that analogy is a kind of extended metaphor or long simile in which an explicit comparison is made between two things (events, ideas, people, etc.) for the purpose of furthering a line of reasoning or drawing an inference, a form of reasoning employing comparative or parallel case.

\section{RhetORICAL FunCtions OF ANALOGY}

Analogy aims at what is common between two things of different classes. One is an unfamiliar subject, usually a difficult or abstract subject the writer makes a point of clarifying. The other is a familiar subject, normally an easy subject the writer utilizes to help explain his unfamiliar subject. But the key point which makes it distinct from other figurative comparison, like simile or metaphor, is it tends to suggest that existing similarities imply even more similarities. Thus not only is analogy a figurative comparison, but also a logical reasoning. The following is a typical example:

The chess-board is the world; the pieces are the phenomena of the universe; the rules of the game are what we call the laws of Nature. The player on the other side is hidden from us. We know that his play is always fair, just and patient. But also we know, to our cost, that he never overlooks a mistake, or mistakes the smallest allowance for ignorance. To the man who plays well, the highest stakes are paid, with that sort of overflowing generosity with which the strong shows delight in strength. And one who plays ill is checkmated-without haste, but without remorse.

In the above example, the author, Thomas Henry Huxley, uses the analogy of two players in a chess game to explain that Man will succeed only if he plays by the laws of Nature. Maybe at the first glance, a reader may think that since Nature (the other side of the game) has been humanized, the rhetorical device, personalization has been employed, making abstract Nature more specific and familiar to the reader. To somehow, it is to the non-human being Nature that human's qualities and abilities to play game and to have human's intelligence have been attributed. But from a more abstract and comprehensive perspective, an analogy has been used here to establish the pattern of reasoning by using familiar argument which the reader can understand easily and agree with. 


\begin{tabular}{|l|l|l|}
\hline Structure & Simile/ Metaphor & Analogy \\
\hline Method & Concentrates on one point of resemblance & $\begin{array}{l}\text { Draws a parallel between two unlike things that have } \\
\text { several common qualities or points of resemblance }\end{array}$ \\
\hline Function & $\begin{array}{l}\text { Serve to heighten effect; to enhance the } \\
\text { subject }\end{array}$ & By reasoning \\
\hline Core & Characteristic(s) in common & $\begin{array}{l}\text { For the purpose of persuasion or for the explanation or } \\
\text { exposition of an idea }\end{array}$ \\
\hline
\end{tabular}

Analogy compares two things, which are alike in various respects, for the purpose of explaining or clarifying same unfamiliar or complex ideas or object by showing how the idea or object is similar to a familiar one. Analogy is chiefly used for the purpose of persuasion or for the explanation or exposition of an idea.

The function of analogy differs also from that of simile or metaphor. While the latter figures serve to heighten effect with vivid imagery, analogy is chiefly used for the purpose of persuasion or for the explanation or exposition of an idea.

\section{Structural Patterns of Analogy}

Analogy isn't just a form of speech. It can be a logical argument: if two things are alike in some ways, they are alike in some other ways as well. Analogy is often used to help provide insight by comparing an unknown subject to one that is more familiar. It can also show a relationship between pairs of things. This form of analogy is often used on standardized tests in the form "A is to B as C is to D." Here are the typical structural patterns of it:

A. A without B is (like) $C$ without $D$ (or $A$ with $B$ is like $C$ with D)

1) A woman without a man is like a fish without a bicycle.

2) Beauty without grace is like the hook without the bait.

3) To go to the palace with just a flower is to say "I'm poor, I haven't any jewelry."

B. A is to $B$ as $C$ is to $D$

1) Air is to man as water is to fish.

2) Shoe is to foot as tire is to wheel.

3) Food is to man as fuel is to engine.

4) Reading is to the mind what food is to the body.

C. $A$ is to $B$ what $C$ is to $D$ (or: $A$ to $B$ is what $C$ is to $D$, or what $C$ is to $D, A$ is to $B$ )

1) What salt is to food, wit and humor are to conversation and literature

2) Judicious praise is to children what the sun is to flowers.

3) What sculpture is to a block of marble, education is to the soul.

4) The man who cannot be trusted is to society what a bit of rotten timber is to a house.

D. (Just) as A...B, (so) C...D (or: ...so C ...D, just as A...B)

1) Just as the French like their wine, so the English like their bear.

2) Just as Darwin discovered the law of organic nature, so Marx discovered the law of development of human history.

3) As cold waters to a thirsty soul, so is good news from a far country.

E. If A were $B, C$ would...D

1) If society were a train, the etiquette would be the rails along which only the train could rumble forth; if society were a state coach, the etiquette would be the wheels and axis on which only the coach roll forward.

2) If love were what the rose is, And I were like the leaf, Our lives would grow together

In sad or singing weather, Blown fields or flowerful closes,

$\ldots$

If love were what the rose is,

And I were like the leaf.

(by A. Charles Swinburne)

\section{F. Other Sentence Patterns}

1) The Negros has a callus growing on his soul and it's getting harder and harder to hurt him there. That is a simple law of nature. Like a callus on the foot in a shoe that is too tight. The foot is nature's and that shoe was put on by man. The tight shoe will pinch your foot and make you scream in pain. But sooner or later, if you don't take the shoe off, a callus will form on the foot and begin to wear out the shoe. It is the same with the Negro in America. That shoe- the white men's system - has pinched and rubbed and squeezed his soul until it has almost destroyed him. But it didn't. And no w a callus has formed in his soul, and unless that sys tem is adjusted to fit him, too, that callus, is going to wear out 
that system.

\begin{tabular}{|l|l|l|}
\hline & Tenor & Vehicle \\
\hline & Foot & The soul of the Negro \\
\hline \multirow{2}{*}{ Parallel Similarities } & The tight shoe & The white men's System \\
\cline { 2 - 3 } & The callus on the foot & The callus on the soul (racial discrimination) \\
\hline Conclusion & The callus will finally begin to wear out the shoe. & The unfair social situation will press the Negros to rebel. \\
\hline
\end{tabular}

2) Have you ever watched a clumsy man hammering a nail into a box? He hits it first to one side, then to another, perhaps knocking it over completely, so that in the end he only gets half of it into the wood. A skillful carpenter, on the other hand, will drive home the nail with a few firm, deft blows, hitting it each time squarely on the head. So with language; the good craftsman will choose words that drive home his point firmly and exactly. A word that is more or less right, a loose phrase, an ambiguous expression, a vague adjective, will not satisfy a writer who aims at clean English. He will try always to get the word that is completely right for his purpose.

\begin{tabular}{|l|l|l|}
\hline & Tenor & Vehicle \\
\hline \multirow{5}{*}{$\begin{array}{l}\text { Parallel } \\
\text { Similarities }\end{array}$} & $\begin{array}{l}\text { A carpenter's job (A man hammering a } \\
\text { nail into a box) }\end{array}$ & A writer's job (An author's choosing a word) \\
\cline { 2 - 3 } & A nail & A writer \\
\cline { 2 - 3 } & A box & A word \\
\cline { 2 - 3 } & $\begin{array}{l}\text { The nail half of it into the wood by a } \\
\text { clumsy carpenter }\end{array}$ & $\begin{array}{l}\text { More or less right, a loose phrase, an ambiguous } \\
\text { expression, a vague adjective by a mean writer. }\end{array}$ \\
\hline Conclusion & $\begin{array}{l}\text { A skillful carpenter, on the other hand, will } \\
\text { drive home the nail with a few firm, deft } \\
\text { blows, hitting it each time squarely on the } \\
\text { head. }\end{array}$ & $\begin{array}{l}\text { An ineffective or an inappropriate word will not } \\
\text { satisfy a writer who aims at clean English. He } \\
\text { will try always to get the word that is completely } \\
\text { right for his purpose. }\end{array}$ \\
\hline
\end{tabular}

3) The trouble is that the English nature is not at all easy to understand. It has a great air of simplicity, it advertises itself as simple, but the more we consider it, the greater the problems we shall encounter. People talk of the mysterious East, but the West also is mysterious. It has depth that do not reveal themselves at the first gaze. We know what the sea looks like from a distance: It is of one color and level, and obviously cannot contain such creatures as fish. But if we look into the sea over the edge of a boat, we see a dozen colors and depth below depth, and fish swimming in them. That sea is the English character-apparently imperturbable and even. The depths and the colors are the English romanticism and the English sensitiveness - we do not expect to find such things, but they exist. And - to continue my metaphor - the fish are the English emotions, which are always trying to get up to the surface, but do not quite know how. For the most part we see them moving far below, distorted and obscure. Now and then they succeed and we exclaim, "Why, the Englishman has emotions! He actually can feel!" And occasionally we see that beautiful creature, the flying fish, which rises out of the water altogether into the air and the sunlight. English literature is a flying fish. It is a sample of the life that goes on day after day beneath the surface; it is a proof that beauty and emotion exist in the salt, inhospitable sea.

4) In the dark night of the desert a group of scientists is testing a new device for guiding a missile to its target. Designed to seek out the heat of an enemy aircraft engine, it is now going through its paces by tracing the movement of a flashlight waving thirty feet away in the darkness. A hundred yards away, unseen by the men, an equally deadly missile is searching out its prey. Sliding between the stones of the desert, a rattlesnake senses a patch of warmth. Without a sound the snake closes it and strikes for the kill. Those two incidents dramatize one of the newest and most fascinating investigations of modern science. For the simple fact is that the missile's heat seeker, with its few thousand pounds of electronic gadgets, is huge and clumsy compared to the snake's. Although the snake's mechanism is small enough to be packed into a head the size of a walnut, it can detect a change in temperature of one-thousandth of a degree. T he men working on the missile finder would dearly love to know how, for no manmade device can equal this.

\begin{tabular}{|l|l|l|}
\hline & Tenor & Vehicle \\
\hline \multirow{4}{*}{$\begin{array}{l}\text { Parallel } \\
\text { Similarities }\end{array}$} & $\begin{array}{l}\text { A manmade complicated electronic gadget } \\
\text { which is not within normal people's knowledge }\end{array}$ & A natural phenomenon familiar to everyone \\
\cline { 2 - 3 } & A new device & A rattlesnake \\
\cline { 2 - 3 } & The target & Its prey \\
\cline { 2 - 3 } & The heat of the enemy aircraft engine & A patch of warmth \\
\cline { 2 - 3 } & $\begin{array}{l}\text { The missile's heart seeker, with its few } \\
\text { thousand pounds of electronic gadgets }\end{array}$ & $\begin{array}{l}\text { The snake's mechanism, small enough to be packed into a head } \\
\text { the size of a walnut }\end{array}$ \\
\hline Conclusion & Manmade device is huge and clumsy & The snake's sense organ is small but sensitive and practical. \\
\hline
\end{tabular}

5) Social insects live in integrated communities which in some ways are similar to human communities. In both types of community there is a division of labor. In insects' societies certain insects are responsible for production; the workers collect food while the soldiers defend the colony. In the same way human groups such as farmers and shopkeepers have specialized function in producing goods and providing services to the community. 
Insect and human societies are also alike in that individual members of the community work together. Termite workers coordinate their efforts to build nests. Similarly in human societies, engineers, architects, town planners and construction workers unite to build cities.

The nests of social insects are as complex as a manmade city. In some insect nests special accommodation is provided for the young and for food storage. Many nests also have devices for regulating the temperatures. So insect nests are as functional as human houses.

\begin{tabular}{|l|l|l|}
\hline & Tenor & Vehicle \\
\hline & Social insects & Human societies \\
\hline \multirow{2}{*}{$\begin{array}{l}\text { Parallel } \\
\text { Similarities }\end{array}$} & In both types of communities there is division of labor. \\
\cline { 2 - 2 } & Individual members of both communities work together. \\
\cline { 2 - 2 } & The nests of social insects are as complex and functional as human houses. \\
\hline Conclusion & $\begin{array}{l}\text { Social insects live in integrated communities which in some ways are similar to human } \\
\text { communities. (The first sentence of this passage) }\end{array}$ \\
\hline
\end{tabular}

6) Some old people are oppressed by the fear of death... The best way to overcome it — so at least it seems to me-is to make your interests gradually wider and more impersonal, until bit by bit the walls of the ego recede, and your life becomes increasingly merged in the universal life. An individual human existence should be like a river-small at first, narrowly contained within its banks, and rushing passionately past rocks and over waterfalls. Gradually the river grows wider, the banks recede, the waters flow more quietly and in the end, without any visible break, they become emerged in the sea, and painlessly lose their individual being. The man who, in old age, can see his life in this way, will not suffer from the fear of death, since the things he cares for will continue...

\begin{tabular}{|l|l|l|l|}
\hline & \multicolumn{2}{|l|}{ Tenor } & Vehicle \\
\hline & Human's Life & A River \\
\hline $\begin{array}{l}\text { Parallel } \\
\text { Similarities }\end{array}$ & Early Age & $\begin{array}{l}\text { Childish, } \\
\text { naive }\end{array}$ & $\begin{array}{l}\text { Small at first, narrowly contained within its } \\
\text { banks }\end{array}$ \\
\cline { 2 - 4 } & Adolescence & $\begin{array}{l}\text { Youthful, } \\
\text { energetic }\end{array}$ & $\begin{array}{l}\text { Rushing passionately past rocks and over } \\
\text { waterfalls. }\end{array}$ \\
\cline { 2 - 4 } & Middle Age and old Age & $\begin{array}{l}\text { Experienced, } \\
\text { mature }\end{array}$ & $\begin{array}{l}\text { Gradually the river grows wider, the banks } \\
\text { recede, the waters flow more quietly }\end{array}$ \\
\cline { 2 - 4 } & Death & Quiet & $\begin{array}{l}\text { In the end, without any visible break, they } \\
\text { become emerged in the sea. }\end{array}$ \\
\hline Conclusion & $\begin{array}{l}\text { The best way to overcome it is to make your } \\
\text { interests gradually wider and more impersonal } \\
\text { because death is a natural part of life. }\end{array}$ & $\begin{array}{l}\text { All rivers flow to the sea and finally emerge } \\
\text { into the sea. }\end{array}$ \\
\hline
\end{tabular}

\section{G. A Whole Story or an Entire Book}

Analogy can reveal itself in a single sentence, a paragraph, a discourse, or even an entire book. The best seller Who Moved My Cheese written by Dr. Spencer Johnson is just a typical example of an analogy, through which the author has made a vivid picture of the explanation, making the story more specific, more impressive and of more artistic appeal. In Lesson Twelve "The Loons" of Advanced English Book One, an analogy is also employed in the whole story to demonstrate theme - the miserable fate of marginalized half-breeds in the white culture.

\begin{tabular}{|l|l|l|}
\hline & Tenor & Vehicle \\
\hline & The loons & The half-bred Indians represented by Piquette \\
\hline $\begin{array}{l}\text { Paralleled } \\
\text { Similar Points }\end{array}$ & The loons only sing at night & $\begin{array}{l}\text { Piquette hides her feelings and wishes from others and } \\
\text { is always self-caged and on guard against others with a } \\
\text { mask. }\end{array}$ \\
\cline { 2 - 3 } & $\begin{array}{l}\text { The loons' habitat was destroyed by } \\
\text { human. }\end{array}$ & $\begin{array}{l}\text { The half-bred Indians' home was invaded and occupied } \\
\text { by the White. }\end{array}$ \\
\cline { 2 - 3 } & The loons disappeared at last. & $\begin{array}{l}\text { Piquette's attempt to pursue new life failed and she died } \\
\text { finally. } \\
\text { The Indians can not find their position in the } \\
\text { white-dominating society. }\end{array}$ \\
\cline { 2 - 3 } & $\begin{array}{l}\text { Nature has been ruined by } \\
\text { civilization. }\end{array}$ & $\begin{array}{l}\text { The half-bred Indians have been marginalized and } \\
\text { squeezed out of the society. }\end{array}$ \\
\hline Conclusion & $\begin{array}{l}\text { The extinction of the loons should } \\
\text { awake us in the social development. }\end{array}$ & $\begin{array}{l}\text { The miserable destiny of the half-bred Indians } \\
\text { represented by Piquette should be changed and this } \\
\text { social problem needs solving. }\end{array}$ \\
\hline
\end{tabular}

\section{CONCLUSION}

Language is also full of analogies that can vary by region or by groups of people. Analogy is chiefly used for the purpose of persuasion or for the explanation or exposition of an idea and is offered to provide insights, and can be very instructive. This rhetorical device is a technique of using language that will increase the persuasiveness of the speaking 
and the writing. We should be clear about the implications drawn from parallel comparisons.

Analogy can manifest itself in a single sentence, a paragraph, a discourse, or even an entire book. From the perspective of sentence pattern of this structurally simile/metaphor-based figure, there are some distinctly marked but frozen and fixed structures.

While an analogy sets out to persuade or to explain, it does not necessarily set out to prove. Sometimes an analogy can be carried too far, and mislead rather than convince. When writing analogies, we should carry a paralleled comparison based on logical and reasonable association.

\section{REFERENCES}

[1] Crystal, D. (1997). The Cambridge Encyclopedia of Language. Cambridge: Cambridge University Press.

[2] Gentner D. (2001). The Analogical Mind: Perspectives from Cognitive Science. Cambridge: MIT Press, 224.

[3] Gentner D, Arthur B. (1997). Structure Mapping in Analogy and Similarity. American Psychologist 1, $49-67$.

[4] George A. Kennedy. (1999). Classical Rhetoric and its Christian and Secular Tradition from Ancient to Modern Times. Chapel Hill and London: The University of North Carolina Press.

[5] Hudson, R. A. (1984). Sociolinguistics. Beijing: Foreign Language Teaching and Research Press.

[6] Mona Baker, Gabriela Saldanha. (2004). Routledge Encyclopedia of Translation Studies. Shanghai: Shanghai Foreign Language Education Press, 167-173.

[7] Peter Newmark. (1981). Approaches to Translation. Shanghai: Shanghai Foreign Language Education Press, 38-43.

[8] Sonja K. Fossetal. (1985). Contemporary Perspectives on Rhetoric. Illinois: Waveland Press, Inc.

[9] Walter Nash. (1989). Rhetoric: The Wit of Persuasion. Oxford: Basil Blackwell Ltd. Co.

[10] Xu Youcai. (1992). Modern English Stylistics. Zhengzhou: Henan University Press.

Yan Chang was born in Jingzhou, China in 1981. She received her M.A. degree in foreign linguistics and applied linguistics from Ocean University of China in 2006.

She is currently a lecturer in the School of Foreign Languages, Qingdao University of Science and Technology, Qingdao, China. Her research interests include linguistics, English rhetoric and translation. 